\title{
Sobre pontos de partida: planejamento em comunicação $e$ integralidade da atenção em saúde
}

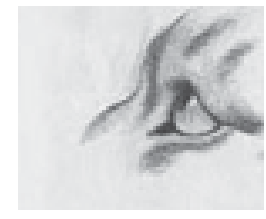

Áurea Maria da Rocha Pitta ${ }^{1}$ Francisco Javier Uribe Rivera ${ }^{2}$

PITTA, A. M. R.; RIVERA, F. J. U. The starting point: a methodological proposal for communication planning, based on comprehensive healthcare. Interface - Comunic., Saúde, Educ., v.10, n.20, p.395-410, jul/dez 2006.

The text proposes, as a starting point of communication planning, an analysis of Strategic Situational Planning - ("PES"), widely disseminated in the area of collective health. It discusses the relationship between concepts used in Strategic Situational Planning and political economics of the significant. The authors wrote the paper based on both the authors own opinion and that of others regarding institutional dynamics and health-citizen relationship at a local level.

KEY WORDS: health communication. health services. health care (public health).

O texto propõe, como ponto de partida do planejamento em comunicação, o momento explicativo do Planejamento Estratégico Situacional - o PES, largamente difundido no campo da saúde coletiva. Tece relações entre noções que permeiam o PES e uma economia política do significante. Possui como base diferentes momentos da produção e ausculta dos autores a dinâmicas institucionais e relações serviços de saúdepopulação em âmbito local.

PALAVRAS-CHAVE: comunicação em saúde. serviços de saúde. atenção à saúde.

\footnotetext{
${ }_{1}^{1}$ Pesquisadora, Departamento de Comunicação e Saúde/CICT, Fundação Oswaldo Cruz/FIOCRUZ. <aureapitta@cict.fiocruz.br> 2 Pesquisador, Departamento de Administração e Planejamento de Saúde, Escola Nacional de Saúde Pública, ENSP/FIOCRUZ. <uribe@ensp.fiocruz.br>
}

${ }^{1}$ Praia de Botafogo, 96/1906 


\section{Introdução}

A história dos movimentos sociais, acadêmicos e profissionais do campo da saúde coletiva vem apontando, há mais de quatro décadas, para novas lógicas de organização dos modelos de atenção à saúde assentadas no conceito de integralidade da atenção e das necessidades de saúde.

Neste texto procuramos resgatar o que consideramos ser um ponto nevrálgico das políticas de comunicação social no âmbito dos serviços $e$ das instituições de saúde, de forma a contribuir não apenas para a construção de uma necessária coerência destas metodologias com os propósitos de uma política pública de comunicação para a saúde, mas para a definição de linhas de apoio e fomento que possibilitem a viabilidade efetiva de implementação de outros modos de compreender e definir prioridades de investimentos em projetos e ações neste campo, em que são investidos, anualmente, recursos nada modestos do orçamento público.

Se o debate no campo dos modelos tecno-assistenciais e de atenção, com base em necessidades de saúde, vem sendo retomado com bastante consistência e visibilidade nos últimos anos, ainda é pontual e episódico no que diz respeito a um enfoque público de comunicação no campo da saúde coletiva.

Para tanto, valendo-nos da definição sumária de três possibilidades de pontos de partida para o planejamento em comunicação, que precisam ser "desconfundidos", pretendemos contribuir para a reflexão teóricometodológica sobre as relações ("radicais", digamos) entre um enfoque público de comunicação e uma política pública de saúde que tenha como ponto de partida a lógica das necessidades sociais e de saúde. Tentaremos, aqui, um primeiro delineamento de possíveis fronteiras teóricometodológicas sobre a questão.

Uma primeira forma de planejar é aquela desenvolvida pela livre iniciativa no exercício de uma dada "liberdade de imprensa". São diversificadas $e$ bastante complexas as articulações entre empresas do chamado complexo informativo-publicitário - constituído por rádios, TVs privadas, empresas de publicidade e propaganda, entre outras, e empresas voltadas ao consumo de bens e serviços relacionados a saúde-doença. Os fortes condicionamentos de natureza lucrativa, na grande maioria das vezes, acabam por permear a definição da agenda de temas em circulação na dimensão pública. Condicionamentos que acabam por definir uma menor ou maior visibilidade de questões que integram a "ordem do dia" do mercado das Comunicações ${ }^{3}$. Os discursos em saúde-doença e Ciência e Tecnologia (CETT) em saúde são produzidos e circulam, portanto, com base nas relações de produção e nos processos de trabalho que entrelaçam os interesses de mercado da grande mídia, em especial, os dos complexos médico-industrial, do laser, da beleza $e$ juventude, do fitness (Luz, 2006), entre outros, como os de bebidas alcoólicas e medicamentos. Soma-se a isto, o (desigual) acesso e possibilidades de expansão deste padrão de discursividade às novas velocidades hoje permitidas pelas (tele)comunicações e internet, deste mesmo mercado. A conseqüência de tomarmos o que já circula neste mercado como ponto de partida do planejamento em comunicação nos faz incorrer no risco de considerar este o espaço privilegiado de definição de

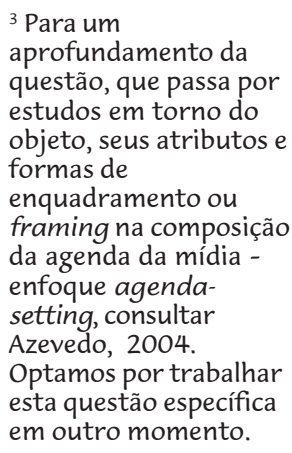

${ }^{3}$ Para um aprofundamento da questão, que passa por estudos em torno do objeto, seus atributos e formas de enquadramento ou framing na composição da agenda da mídia enfoque agendasetting, consultar Azevedo, 2004. Optamos por trabalhar esta questão específica em outro momento. 
${ }^{4}$ No caso da aids, ressaltamos o

diferencial de uma política de comunicação bastante inclusiva no que diz respeito aos atores que a enunciam dada a força dos movimentos nacionais $e$ internacionais em torno da pandemia.

${ }^{5}$ Ainda reduzida a análises em torno dos impactos do "dia D". critérios de relevância pública das questões ligadas à saúde, doença, vida $e$ morte. É o caso, muitas vezes, de alguns programas em canais

governamentais que, para assumirem ares de atualidade e afinidade com os temas tratados na grande mídia, se alinham pontual ou permanentemente à lógica de agendamento aí presente, subvertendo, na maior parte das vezes, os critérios de relevância pública a que deveriam estar atentos. Resultado: grandes descompassos das possíveis escolhas com um temário mais coerente com a lógica das necessidades sociais e de saúde.

Um segundo ponto de partida, usual no planejamento setorial em comunicação, são os próprios sistemas de informações em saúde e suas bases de dados e estatísticas, que se estruturam com base na relação entre demanda e oferta disponível nos serviços de saúde locais. Neste caso, podemos citar como exemplo os grandes investimentos em comunicação que tomam de nossas bases de dados, em especial, doenças de notificação compulsória e de grande interesse transfronteiras, como o caso da aids ${ }^{4} e$ da dengue ${ }^{5}$, em detrimento de outras tantas, como a esquistossomose, doença de chagas, malária e hanseníase.

A partir da década de 1990, identifica-se uma crítica à insuficiência desta modalidade de planejamento em comunicação, baseada em doenças ou entidades nosológicas acolhidas por sistemas de informação organizados segundo uma racionalidade normativa de planejamento em saúde (Rivera, 1995) e transformada em produtos ou compostos de publicidade $e$ propaganda (diferentes "campanhismos"), já que o que se passa no campo da oferta de serviços, nos campos da clínica e da epidemiologia e vigilâncias, em muito se distancia daquilo que lhes é demandado ou permanece não identificado pelas instituições de saúde junto ao público.

Esse condicionamento da demanda pela própria oferta de serviços acaba por permitir, na melhor das hipóteses, o compromisso de equipes de saúde com uma "integralidade possível", já que, por mais comprometidos que possam ser os profissionais de uma equipe de saúde e por mais comunicacionais que sejam as suas práticas, jamais esta integralidade será plena, já que essa plenitude passa pela melhoria das condições de vida e pelo acesso a tecnologias para prolongar a vida (Cecílio, 2006).

No sentido dessa "integralidade possível", diferentes alternativas $e$ propostas emergem desde a década de 1970. Surgem perspectivas de trabalho em rodas (Campos, 2005) e redes de conversação no momento do acolhimento nos serviços de saúde. Momento em que a questão democrática se manifesta na sua forma mais plena e humana - uma riqueza só percebida nesses espaços onde se podem exercitar micropolíticas coerentes com o que é chamado de "democracia viva em ato", que permite, na prática cotidiana, cultivar, na rigidez dos processos de organização da assistência e seus "dispositivos técnico-assistenciais", a ausculta ao que se chamou com muita propriedade de "poéticas sociais" (Teixeira, 2003).

Haveria uma incapacidade, apontada por diferentes autores, de ausculta dos serviços à totalidade do fenômeno saúde-doença (não apenas no campo da clínica), que se expressa pela proliferação de queixas "para além da oferta" disponível. Muitos dos casos, segundo os técnicos e gestores, são identificados como doenças da emoção, como vamos chamar aqui e, em seu limite, encaminhadas a psicólogos ou mesmo a serviços de psiquiatria e... 
medicalizados. Outros tantos, carregados de um sofrimento social indistinto e com queixas diversas em relação à família $e$ ao trabalho, dão entrada nos sistemas de informações locais da unidade na categoria "queixas difusas", que expressam agravos biopsicossociais ou um "sofrimento" e "mal-estar" difusos (Valla, 1999 e Luz, 2001, apud Lacerda \& Valla, 2005). Essas situações escapam às metodologias de planejamento setorial desatentas ao sofrimento humano e às suas poéticas - os mais relevantes referentes éticopolíticos de ações comprometidas com a equidade $e$ a integralidade da atenção à saúde.

Abrem-se perspectivas e reflexões sobre o trabalho com "pessoas em sofrimento", com experiências de vida complexas, cujas necessidades transbordam dos muros das unidades de saúde, e para as quais o espaço do acolhimento no mundo dos serviços de saúde é apenas parte de demandas mais amplas por um bem-estar que deve necessariamente estar expresso no cotidiano da moradia, renda, do trabalho, da família e dos grupos e redes de pertencimento.

Trazendo as redes de conversa para a dimensão mais ampla do espaço das cidades, defendemos, como ponto de partida para o desenho de estratégias de comunicação com vistas à integralidade da atenção, uma "rede de conversações" com base em problemas de saúde compartilhados por grupos sociais de um determinado espaço-população - redes sociodiscursivas.

Desta noção de "rede de conversações" mais ampla e que ultrapassa os muros das unidades de saúde como "espaço físico", é necessário ressaltar algumas questões: uma delas, que a conversação ou a comunicação ${ }^{6}$, passa, em si, a se tornar o ponto de partida para a definição do leque de ações instrumentais de comunicação a serem definidas, agora a partir da lógica das necessidades em saúde-doença.

Vários autores brasileiros, como Mehry (2004), Campos (2003) e Teixeira (2003), sustentam esta noção de rede de conversações no interior do sistema de serviços. Para Teixeira (2003), o acolhimento é uma forma de diálogo (a base do acolhimento é a conversação), orientado a distinguir e hierarquizar necessidades, ajudando, assim, a definir a trajetória ou os fluxos do paciente pelo sistema, ou seja, colaborando para a sua integração sistêmica. Mehry chama a atenção para uma ampliação da noção de acolhimento nas interfaces entre serviços, níveis de complexidade diferenciados de atenção e profissionais de saúde. As relações entre esses níveis corresponderiam a uma rede de petições e compromissos que permitiria garantir essa integração. Neste particular, o autor se apropria da concepção lingüística das organizações (Flores, 1989), segundo a qual a organização é uma rede de conversações recorrentes e o ponto de partida é sempre uma demanda social - ou uma petição. Para o autor, essa rede pode ser rastreada e se constituir em um sistema de monitoramento de compromissos com instrumentos adequados, valendo-se de determinados softwares (por exemplo, o Coordenador).

Da mesma forma, Campos (2005) assinala que o ideal de uma clínica ampliada seria articular o melhor da clínica a uma preocupação com a subjetividade (com o eu) e uma preocupação com o contexto social do usuário. $\mathrm{O}$ autor chama a atenção para a necessidade de uma escuta acurada do sujeito envolvido na relação terapêutica e para as variações clínicas
${ }^{6}$ Os autores fazem a opção por não discutir aqui as possíveis diferenças entre as terminologias. 
decorrentes dos planos da subjetividade e do contexto social. Para Campos, uma clínica do sujeito implicaria, portanto, articular a clínica a um agir comunicativo (Campos, 2005).

Tanto Teixeira quanto Campos ressaltam uma dimensão comunicativa ou conversacional da atenção e se referem à necessidade de equipes multiprofissionais, dada a impossibilidade de um único profissional deter todo conhecimento necessário ao diagnóstico e à terapêutica de situações particulares. Esses autores reforçam, portanto, uma concepção organizacional como rede conversacional, ligada à perspectiva da integralidade.

O que propomos, aqui, é uma ampliação desta concepção para fora dos muros dos serviços. O mapeamento dessas redes sociais extramuros e a ausculta aos discursos sociais para além da relação oferta-demanda junto aos serviços significa, em última análise, levar em consideração uma discursividade ampliada capaz de redefinir uma agenda pública e demandas sociais informadas por um conceito ampliado de saúde, com a perspectiva da promoção da saúde e da intersetorialidade das ações. Este trabalho com grupos e redes de pertença no espaço do território (em muitos casos já desenvolvido por profissionais, agentes de saúde, organizações políticas $e$ sociais) instiga, ainda, uma reflexão sobre possíveis empregos de novas tecnologias de comunicação que possam dar visibilidade pública a essa rede ampliada de conversações. Uma rede pública de desenho ("design") inclusivo e participativo, capaz de agregar aos processos de explicação situacional recursos que permitam o empoderamento e posicionamento público de atores sociais envolvidos com o problema explicado.

Cabe ressaltar que os problemas de saúde, tomados como uma realidade insatisfatória e identificados como relevantes por um determinado indivíduo ou grupo, quando analisados em sua totalidade, com base em abordagens situacionais e comunicativas, não devem ser entendidos como "objetos dados que se oferecem passivamente a observação", mas como conseqüência de uma "negociação complexa entre vários atores, cujos resultados são contingentes e instáveis ao longo do tempo" (Camargo Jr., 2005).

Tomando a crítica ao Planejamento Estratégico Situacional - PES - na sua abordagem comunicativa (Rivera, 1995), é o "momento explicativo" desta modalidade de planejamento o ponto de partida mais coerente com o planejamento de qualquer ação com vistas às necessidades sociais e de saúde. Para alguns autores, como Mendes (1996), Rivera (2003), Artmann (2000) e Lefévre \& Lefévre (2004), o PES é um enfoque de planejamento particularmente útil para a promoção de formas de coordenação horizontal no interior de grandes e pequenas organizações de qualquer natureza, por trabalhar com problemas explicados de uma forma totalizadora, apontando causas ou nós críticos que dependem de vários setores, unidades $e$ departamentos, mas que enfrentam questões em comum a partir de processos de trabalho, técnicas e operações de natureza transversal à organização (Quadro 1). O caráter totalizador do momento da chamada "explicação situacional" do PES, portanto, fortalece e facilita um enfoque de intervenção marcado pela intersetorialidade; daí sua importância metodológica no que diz respeito à noção de promoção da saúde, concebida como paradigma da vigilância à saúde. 
PITTA, A. M. R.; RIVERA, F. J. U.

Quadro 1. Dois enfoques de planejamento para a área social*

\section{Planejamento normativo em Comunicação}

Postulado 1. A planificação supõe um "sujeito" que planeja Postulado 1. O "sujeito" que planeja está compreendido no "objeto um "objeto". O sujeito é o Estado e o objeto é a realidade planejado". Por sua vez, o objeto planejado compreende outros socioeconômica. O sujeito e o objeto planejado são sujeitos que também planejam. É impossível distinguir o sujeito do independentes, e o primeiro pode "controlar" o segundo.

planejamento e o objeto planejado; ambos se confundem: não são independentes. Um ator que planeja não assegura de antemão sua capacidade de controlar a realidade planejada, porque ela depende da ação do outro.

Postulado 2. O sujeito que planeja deve previamente "diagnosticar" a realidade para conhecê-la. Esse diagnóstico se orienta pela busca da verdade objetiva, que deve ser única e absoluta. Há um só ator que planeja, um só diagnóstico, um só conceito do tempo e uma verdade única e absoluta.

Postulado 3. Para compreender a realidade e adquirir capacidade de previsão de sua futura evolução, é necessário descobrir suas "leis" de funcionamento. Se a realidade é um objeto social, seu funcionamento é reduzível a "comportamentos sociais", ou seja, à reação do homem com as coisas expressadas como uma associação estável entre condutas resultantes e variáveis associadas e condicionantes de tais condutas rotineiras.Toda ação é uma ação-comportamento, exceto a ação do sujeito único que planeja.

Postulado 4. Se o ator que planeja não compartilha a realidade com outros atores de capacidades equivalentes, então, não existem oponentes e o planejamento pode referir-se somente ao econômico-social, seu critério de eficácia pode ser somente econômico, e seu cálculo se restringe a um cálculo econômico. Em conseqüência, o planejamento pode identificar-se com o cálculo normativo de "desenho" de um "deve ser", que é discrepante com o "tende a ser", que revela o diagnóstico. O objeto planejado não "contém" atores sociais capazes de produzir ações estratégicas, mas agentes econômicos sujeitos a comportamentos previsíveis.

Postulado 5.Se o planejamento se refere ao desenho de um "deve ser", então, pode referir-se a uma normativa socioeconômica certa, de onde está eliminada a incerteza e os eventos probabilísticos mal definidos, e de onde o político pode considerar-se como um marco restritivo externo ao plano socioeconômico; não podem existir os "problemas quase-estruturados". frente ao objeto planejado.

Postulado 3. Para compreender a realidade e adquirir capacidade de previsão de acontecimentos futuros, não é suficiente nem possível reduzir a ação humana a "comportamentos" previsíveis. O ator que planeja sozinho não se relaciona com as coisas, senão com outros atores que são oponentes ou aliados. Nessa relação, as ações são irredutíveis a comportamentos: são "cálculos interativos" ou "juízos estratégicos", próprios da interação entre atores sociais. As relações iniciativa-resposta se entrelaçam com as relações causa-efeito. A predição é, de um modo geral, impossível: deve ser substituída pela previsão.

Postulado 4. Se o ator que planeja compartilha a realidade com outros atores que também planejam, então, necessariamente, o planejamento deve abraçar o problema a ser vencido e identificar as possíveis resistências dos outros ao próprio plano. Em conseqüência, o planejamento não se pode confundir com o desenho normativo do "deve ser", mas deve levar em consideração o que "pode ser" e a "vontade de fazer". Por isto, inevitavelmente, o planejamento deve sistematizar o cálculo político e centralizar sua atenção na conjuntura. O planejamento econômico é somente um âmbito do planejamento sociopolítico: as forças sociais e os atores sociais são o centro do plano em vez dos grandes agentes econômicos.

Postulado 5. Desde o momento em que o planejamento de um ator se realiza em um meio ativamente resistente e em conflito com outros atores, o normativo só é um "momento" do estratégico e do operacional, e, em consciência, todo está permeado por forte incerteza. Muitas vezes, não se podem enumerar todas as possibilidades nem identificar probabilidades. Somos obrigados a tratar com "problemas quase-estruturados". Os problemas políticos
Postulado 2. Na realidade coexistem vários atores com capacidades de planejamento diferenciadas. Em conseqüência, há várias explicações da realidade e todas elas estão condicionadas pela inserção particular de cada ator nesta realidade. Não são possíveis o diagnóstico único e a verdade objetiva. Só é possível uma explicação situacional onde cada sujeito explica a realidade a partir da posição de enunciação que ocupa não podem ser considerados como um marco ou como um dado restritivo do econômico; é necessário que estes problemas sejam reconhecidos por meio de variáveis políticas endógenas na sistemática do plano.

Postulado 6. O plano é produto de uma capacidade exclusiva do Estado, se refere a um conjunto de objetivos próprios e, no papel, tem "final fechado", porque a situação terminal é conhecida, e também os meios para alcançá-las. Dadas as certezas dos efeitos causais, tudo se reduz a cumprir o plano para alcançar os objetivos. A racionalidade técnica deve impor-se para encontrar uma solução ótima aos problemas.

Postulado 6. O plano não é um monopólio do Estado. Qualquer força social luta por objetivos próprios e está em capacidade de fazer um cálculo que precede e preside a ação. Em conseqüência, existem vários planos em competição e o conflito, bem como o final, estão sempre "em aberto": há mais possibilidades do que as que podemos imaginar. O problema de cumprir um plano não se limita a manipular variáveis econômicas. As soluções ideais ou ótimas devem ceder lugar às soluções satisfatórias que reconhecem a continuidade dos problemas sociais no tempo.

* extraído e simplificado de Sá, 1993. 
Para Mendes (1996), o PES rompe com a fragmentação de um problema concreto, ou com a departamentalização de uma organização, já que enseja, a partir do paradigma da produção social da saúde, uma perspectiva de análise e intervenção intersetorial. Desta maneira, é extremamente coerente com (e potencializa) o princípio organizativo-assistencial da integralidade, um dos eixos da estratégia da regionalização sanitária. Por outro lado, não devemos esquecer a visão que Matus (1993) tem da explicação como uma aposta argumentativa, o que reforça o caráter intersubjetivo e discursivo da explicação situacional. Apoiado na teoria da argumentação (Toulmin apud Matus,1993), propõe ainda um modelo argumentativo de validação do processo de explicação situacional - perspectiva dialógica de sucessivas $e$ diferenciadas abordagens do real.

Esta literatura começa a ser difundida no Brasil a partir, em especial, do pensamento de Matus, Testa e Rivera, criando vertentes aqui e ali, mas assentando as bases de novos pontos de partida para a ação estratégica $e$ intervenções no campo das políticas sociais e de saúde em países em desenvolvimento com ampla escassez de recursos para investimentos no campo das políticas sociais.

\section{Uma abordagem da noção de problema de saúde}

Um problema de saúde é, como já se tem dito de forma recorrente, um problema inaceitável segundo os sentidos atribuídos à saúde por uma dada cultura. Em nosso heterogêneo arsenal cultural, uma doença na família, uma demanda em saúde não atendida pelos governos, uma indústria poluidora em zona residencial, a presença de criadouros de Aedes aegypti domiciliares e peridomiciliares, a disseminação da aids nas populações de baixa renda e entre os idosos, ou a emergência abrupta da doença de Chagas de forma aguda, são exemplos de questões que podem ser interpretadas como problemas relacionados à saúde individual ou coletiva e que guardam especificidades segundo o contexto em que emergem ou as condições sociais, políticas e, assim, simbólicas, que os sustentam ao longo do tempo.

Perguntas que não querem calar: diante do sofrimento e das necessidades sociais e em saúde, que éthos deve nortear a escolha dos pontos de partida para o planejamento em comunicação? Que conceito de relevância pública deve orientar estas escolhas? Como lidar com situações concretas que acontecem em espaços-sociais ${ }^{7}$ também concretos e passam a demandar recortes e aproximações daquilo que é, por sua natureza, denso, instável e mutante? Que metodologias utilizar para uma maior aproximação possível do real em toda a sua densidade e espessura?

Se o que conseguimos traçar deste real são enquadres, recortes, aproximações, como nos reportam os estudos no campo da Antropologia $e$ das Ciências Humanas em geral, o processo de planejar - com vistas à superação ou redução de um dado problema de saúde a um problema de menor valor e impacto sobre vida das pessoas -, a nosso ver, não pode prescindir de uma teia explicativa, de natureza eminentemente discursiva, que promova a maior aproximação possível à totalidade complexa onde o problema se inscreve. A escolha de um ponto de partida, como a metodologia nos propõe, nem sempre recai naquilo que é mais evidente - na 
doença em si ou nos modos de evitá-la via comportamentos ou estilos de vida saudáveis, mas na rede de causalidades que se entrelaça ao problema e o faz emergir ou se manter inalterável ao longo do tempo. Portanto, é a busca de "nós" críticos o momento crucial da metodologia. É ela que vai definir o melhor ponto de partida de qualquer ação: aqui, em especial, as ações comunicacionais. "Nós" muitas vezes delicados, sutis, apreensíveis por explicações sucessivas de um mesmo problema no momento "vivo" da "explicação" de seu processo de produção social. "Nós" críticos, muitas vezes, altamente resistentes ao interior desse enredamento mutante, dessas formas de determinação de nossas fragilidades - do indivíduo no coletivo $e$ dos coletivos de indivíduos.

É da própria dinâmica dos processos sociais, em sua complexidade, estarem inseridos em contextos específicos que, momento a momento, se transformam discursivamente, apresentando maiores ou menores regularidades, maiores e menores visibilidades sociais, conformando o que chamamos aqui de uma "economia política"8 dos processos de produção discursiva, textual: "do significante" (Pinto, 1994; Pitta, 2004). Com esta postulação, Pinto coloca qualquer diferença de sentido atribuída a dois ou mais discursos sociais, mesmo que pequenas, como determinadas pelas condições de produção de cada discurso em questão, já que o sentido de um "objeto significante", ou como chamou Verón, "pacote significante" (Verón apud Pinto, 1996), ou ainda "texto" (Eco apud Pinto, 1996), é "diferencial", e depende do contexto ou da "situação de comunicação" na qual este objeto é produzido: das dimensões pragmática, histórica $e$ sociocultural dessa situação. Cada uma das múltiplas variáveis situacionais passam, assim, a "imprimir marcas" e "deixar traços de natureza léxicogramatical e retórica" que os diferenciam sempre de um outro, abrindo caminhos para a formulação de uma teoria das operações enunciativas que vincula sentidos, discurso e situações - ou condições concretas de produção dos mesmos. O postulado, enfim, ao negar a existência de uma relação linear e unívoca "significante-significado", liberta o significante de sua prisão, como propõe o autor, já que, ao procurarmos significados, estaremos sempre encontrando novos significantes, processo que constitui o que é chamado de semiose infinita ou intertextualidade (Kristeva, 1975; Verón apud Pinto, 1994). O postulado, finalmente, abre espaço para percebermos a estreita relação existente entre produção do sentido, poder, luta política $e$ luta simbólica, inerentes às relações de dominação, e resistências e negações a ela, que atravessam as práticas sociais.

Passado o momento de sua produção social, e aprisionados em suporte fílmico, impresso, digital, ou outro, os discursos sociais, recolhidos em sua efemeridade, transformam-se em "produtos comunicacionais", que fixam, no tempo, uma determinada proposta de relação entre sujeitos de um processo que já se desfez em vida, já é passado. Passam a conformar, assim, como propõe De Marinis (1982), um outro tempo: um tempo que é representado. Uma pausa no tempo cotidiano. Produtos que, se podem ser analisados por delicados e perspicazes procedimentos de análise do discurso, já não pertencem mais, em termos de temporalidade, à instantaneidade do processo de produção discursiva em seu momento mesmo de produção, de "funcionamento", de ação.
${ }^{8}$ Utilizado, aqui, numa concepção marxiana da produção social do significante, é necessário ressaltar, conforme Pinto, 1994 e Verón, 1980, que nada acede à condição de significante fora de um processo de

comunicação e de troca, e de um conjunto de condições de produção que estabelecem $e$ validam a construção $e$ a existência, no tempo, dos objetos de uma dada cultura. Da mesma forma, destacamos os estudos de Bolaño (2005) sobre a importância e centralidade dos estudos de uma economia política das comunicações na contemporaneidade. 
${ }^{9}$ Desconfundir as coisas continua sendo necessário aqui, já que o termo "comunicação social" se cristalizou ao longo das décadas com diferentes sentidos, inclusive, aqueles que a colocam como área técnica de apoio a garantir a legitimidade (às vezes a qualquer custo) de instituições públicas ou privadas aos olhos do que é da ordem do público (daquilo que é do uso de todos)

${ }^{10}$ Conceito de origem marxiana que é vital, em termos metodológicos, a qualquer abordagem com base numa economia política das trocas simbólicas ou disputas de sentido.

${ }^{11}$ Momento, para Matus, expressa um marco temporário provisório em que se realiza

preferencialmente uma dada fase do

planejamento. É o conceito que distingue, de forma radical, a opção metodológica matusiana daquela do planejamento tradicional em etapas. Lida com as várias fases do planejamento como imbricadas. Ora prevalecendo uma, ora outra, ora outra, mas sempre "tudo ao mesmo tempo e agora", como no jargão popular.
Voltando à nossa questão inicial dos problemas de saúde, passa a ser compromisso ético-político do profissional de comunicação do campo da saúde coletiva, dar o necessário passo atrás no momento de planejar, com vistas a ações coerentes com a noção de integralidade em saúde.

Especialmente quando se tem em conta que a tematização dos problemas de saúde com que lida o profissional de comunicação é orientada quer pelas bases de dados, estatísticas e epidemiologia dos grandes números, quer pelo discurso ritualístico da grande imprensa e suas articulações menos ou mais explicitas com interesses de mercado junto ao senso comum.

Se tratarmos os problemas de saúde com base na teoria da produção social proposta por Matus (Figura 1), em especial, a sua crítica com base no agir comunicativo e na sua vertente habermasiana (Rivera, 1995), chegamos a uma aproximação bastante eloqüente da necessidade de redefinição dos pontos de partida para o planejamento e definição de ações comunicacionais. Sob este ponto de vista, a questão comunicacional no campo da saúde passa a não mais se reduzir a planejamento e elaboração de produtos comunicativos, mas a se conformar como um conjunto mais complexo de processos, estratégias, táticas e inventividades, entre as quais os produtos comunicacionais são apenas parte.

No campo do planejamento "em comunicação" para a área social e de saúde", 9 estamos diante da necessidade de incorporação dos conceitos $e$ noções de tempo, situação, totalidade ${ }^{10}$. De olhar para totalidades discursivas que, ao mesmo tempo em que são regidas por certas regularidades, se movimentam e moldam momento a momento, frame a frame, enquadre a enquadre, e condicionadas pela incerteza, o que chamamos de real. Talvez, desta forma, possamos evitar recortes parciais de objetos e problemas que são, na sua essência, altamente complexos, dada a extrema e veloz plasticidade dos processos sociais e dos sentidos dados a vida, a doença e a morte: em que, ao conceito de momento ${ }^{11}$ (Matus, 1984) pode-se agregar a noção de totalidade discursiva inerente a uma viva $e$ dinâmica economia política do significante (Pinto, 1996).

Para Matus, a realidade social é "produzida" permanentemente pela ação dos sujeitos, dos atores sociais que participam permanentemente de situações e problemas concretos, o que, para a semiologia dos discursos sociais, significa dizer que o discurso social é, em si, o motor da produção da própria realidade e dos objetos de uma dada cultura, ou o próprio objetorelação do planejamento situacional em saúde (Sá, 1993).

Figura 1. Os três âmbitos da produção social (e discursiva) segundo Matus (1993)
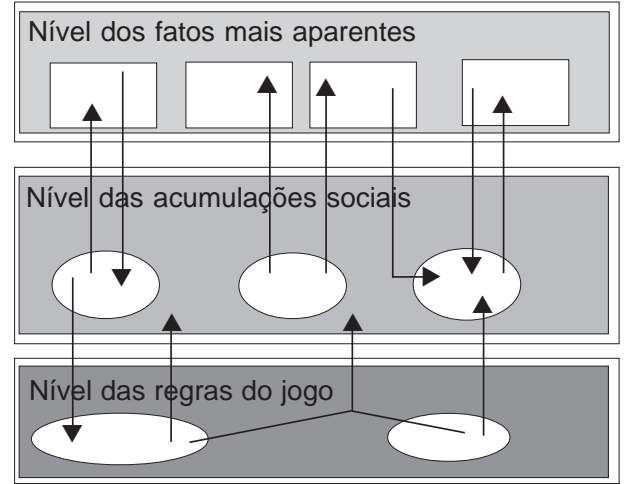
Essa "produção" social e discursiva é descrita por Matus, para fins metodológicos, em três âmbitos. Um primeiro, dos fatos mais aparentes: daquilo que é produzido como discurso por um determinado grupo social, seja na forma de relações interpessoais e no plano tácito, seja em fatos inusitados que ganham o estatuto de "rumor" na vida cotidiana, ou ainda em fatos que, na medida da seletividade com que opera a imprensa e seus dispositivos de enunciação, se transformam em acontecimentos diariamente hierarquizados nos diferentes produtos comunicacionais (em textos acadêmicos, discursos políticos e muitos outros "textos"). Este âmbito, dos processos de produção social, configura o nível mais aparente da vida social (a aparência que assume em público). Podemos observar o movimento dessa produção de forma direta em nossa própria casa, no trabalho, em uma pequena organização ou em espaços mais amplos. Às vezes, não são percebidos dadas as suas sutilezas ou, por vezes, são ruidosos, pela articulação com meios de comunicação que essas produções sociais mobilizam.

Neste primeiro âmbito da aparência, proposto por Matus, como em toda a vida em sociedade, estão a ocorrer diuturnamente disputas de sentidos $e$, assim, de poder - poder de dizer, citar, falar, defender, acusar, mostrar... produzir sentidos. Poderes que, mobilizados pelo discurso em seu mais amplo sentido, dão origem a processos de produção de consensos e dissensos, de acumulação/desacumulação de novos poderes. Assim se conformam, nesses enredamentos discursivos, "nós de rede" que não representam necessariamente unanimidades, e que se refazem incessantemente ao longo do tempo. Pontos de adensamento de grande plasticidade, em função dos processos de cooperação, negociação ou conflito que aí ocorrem. Por haver sempre dissensos, adotamos aqui a noção de consensos normativos mínimos (Moisés, 1992) que, ao se romperem, desestabilizam "densidades", consensos criam pontos de ruptura. Enfim, atores, encenações, processos de construção $e$ reconstrução de consensos, dissensos, poder e sentidos em disputa permanente.

A nosso ver, é a permanência de consensos mínimos, ao longo do tempo, que confere estabilidade a esses adensamentos discursivos, a ponto de se constituírem grupos, instituições, que podem adquirir desde uma estabilidade relativa ao longo de séculos, a uma instabilidade tal que não os permita sobreviver a décadas, anos, meses ou mesmo dias.

Este segundo âmbito proposto por Matus, o das acumulações, não tem sua dinâmica discursiva interna tão aparente. Para sermos mais precisos, as acumulações, aqui, corresponderiam a esses consensos mínimos que adquirem estabilidade ao longo do tempo e se traduzem em recursos simbólicos ou culturais de poder, em saberes legitimados ou atos de fala coagulados como saberes consensuais (pontos de adensamento), utilizados por atores sociais $e$ políticos, com capacidade de influenciar os outros recursos de poder, políticos, econômicos e organizativos (e de ser influenciados pelos mesmos). Para garantir sua estabilidade e dar visibilidade aos seus consensos mínimos ao longo do tempo, grupos e instituições (atores) precisam reiterá-los permanentemente - contexto a contexto, situação a situação, utilizando ou não meios de comunicação massivos, mas dando visibilidade de forma ritualística a seus discursos no tempo. Situação, aqui, tomada como um construto complexo, dinâmico, permanentemente fugidio, resultado de imbricações, 
${ }^{12}$ Conjunto de constrangimentos situacionais inerentes aos processos de produção do discurso social.

${ }^{13}$ Conceito cunhado por Moisés (1992). transmutações, entrelaçamentos de campos... conformando pontos, "nós", absolutamente singulares de uma complexa rede de interdeterminações que configuram processos de fragilização - individuais ou coletivos - processos saúde-doença (Pitta E Oliveira, 1995). Situações de saúde que são, em si mesmas, situações de comunicação: um entrelaçar de condições de produção discursiva em que os objetos significantes são produzidos e circulam, deixando restos, traços, vestígios em sua efemeridade ou em sua imobilização em suportes materiais.

No entanto, esse âmbito em que o conflito parece estar regulado por um mínimo de acordos (formais ou não) e que acaba condicionando o âmbito das "aparências", às vezes, determina ou condiciona a existência, a nãoexistência ou, mesmo, o silêncio de um sujeito, processo ou objeto - tem consigo o poder de uma espécie de "validação" de determinados padrões de normalidade culturalmente aceitos. É aqui que o que é considerado "deriva" de sentidos ou, ainda, "desrazão" acabam sendo reduzidos a "ruídos", "murmúrios" longínquos para a planificação normativa (Certeau, 1995), expressão de processos de exclusão discursiva e, assim, exclusão social. Neste âmbito, discursos e consensos mínimos que assumem maior regularidade $e$ estabilidade, bem como maior visibilidade nos jogos discursivos, passam a competir agora em uma arena em disputa de suas "verdades" - já que mais estáveis ao longo do tempo, e consagradas socialmente como mais legítimas.

Num terceiro âmbito, a produção social analisada por Matus assume o poder de regra, norma socialmente aceita ou lei a ser acatada, que expressa o arsenal normativo dos poderes das nações e determinam e/ou condicionam os outros dois níveis e, neste, não vamos nos deter.

Se concordamos, ao menos parcialmente, com este tosco desenho de âmbitos dos processos de produção social propostos pelas metodologias do PES, bem como com a idéia da existência de uma economia política do significante à qual pertencem os problemas de saúde-doença, podemos seguir em frente.

\section{Um possível ponto de partida para um planejamento em comunicação com vistas à integralidade da atenção}

Partimos do pressuposto de que os discursos sociais estão em viva relação uns com os outros, conformando uma malha discursiva, intertextual, plural. Entendemos também que são produzidos em contextos sociais específicos que condicionam e "constrangem" esse processo de produção ${ }^{12}$. E, ainda, que os contextos são o palco de um diálogo entre as múltiplas vozes que os instituem e que se expressam na materialidade de encenações, geração de consensos ou dissensos que se alteram ao longo do tempo, que podem ou não adquirir maior ou menor visibilidade no espaço público, na medida em que sobrevivem aprisionados ou impressos em produtos comunicacionais ou culturais de menor ou maior circulação e acesso público.

A compreensão e o reconhecimento dessa rede complexa de mediações discursivas são o ponto de partida conceitual e, conseqüentemente, metodológico do planejamento em comunicação coerente com os propósitos de uma atenção integral à saúde. Um dinâmico fazer e refazer de pontos de adensamento: de construção de consensos normativos mínimos ${ }^{13}$ que se 
entrelaçam na prática política e social cotidiana. Rede que assume, contexto a contexto, situação a situação, sistema a sistema de governo ou projeto de gestão, diferenciais de conflitualidade - portanto, de inclusividade (Pitta, 2001).

Explicar problemas de saúde como ponto de partida do planejamento em comunicação significa não apenas romper com um modelo de planejamento em comunicação que tem como ponto de partida a lógica de produção de informações das bases de dados oficiais, e nas quais domina o olhar técnico ${ }^{14}$. Significa, para os sujeitos enredados em um dado problema de saúde concreto, a possibilidade de delimitar as fronteiras do problema a ser enfrentado, suas causas, conseqüências e o âmbito de seus espaços de ação, experimentando, segundo seus pontos de vista $e$ na condição de sujeitos, as suas próprias possibilidades e habilidades de ação política, de traçar cenários futuros que passam a mobilizar a partir do mundo do desejo, pleno de ações tácitas e estratégias - movendo-se como agentes de transformação de sua própria realidade insatisfatória.

Se esta proposta metodológica "estratégica-situacional", para uma comunicação pública e com base em necessidades sociais e de saúde concretas não garante o apagamento da distância entre a experiência vivida $e$ as soluções tomadas como consensos, cria, no mínimo, novas possibilidades de buscar, dado o envolvimento dos sujeitos com o problema, estratégias de comunicação com base nos determinantes biopsicossociais do problema a ser enfrentado. A distância ou o afastamento do que é proposto em um primeiro momento só pode ser superado pela construção de novos consensos, e assim sucessivamente: momento a momento do planejamento situacional - uma proposta essencialmente política e, assim, de planejamento e avaliação incessante ao longo do tempo, categoria cara para a metodologia em questão.

A título de exemplo, recuperamos, aqui, um problema de saúde em uma de suas possíveis teias ou enredamento (Quadro 2). A face visível dentro das possibilidades da metodologia, de seus pontos ou "nós" críticos, a serem desfeitos com vistas à redução do problema a um problema de menor valor para o grupo social em questão e a partir dos quais corresponderiam, segundo o ponto de vista aqui discutido, as ações comunicacionais, envolvendo ou não aparatos técnicos ou mídias, como o rádio, tvs, internet e outras tantas em acelerada convergência.
${ }^{14}$ Que tem como ponto de partida os sistemas locais de informações em saúde com base na relação oferta-demanda por serviços. 
Quadro 2. Planejamento em comunicação - sobre pontos de partida

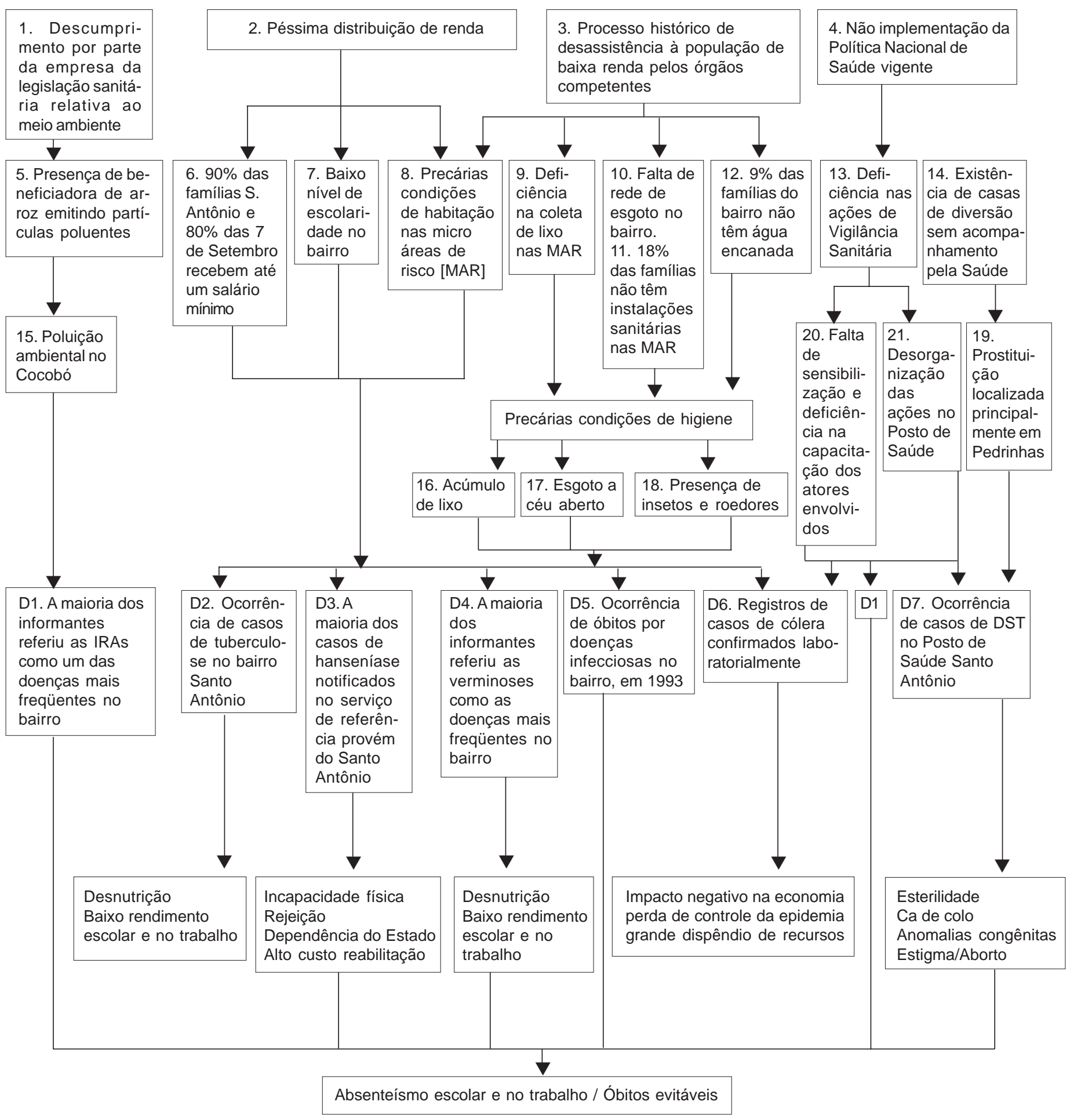

Acurcio \& Santos, 1994. 


\section{A título de novas frentes de trabalho e debate no campo das metodologias de planejamento em comunicação}

Não há como definir, na letra cristalizada de nossos papéis, que estratégias poderiam ser definidas frente ao problema explicado no exemplo - problema explicado "em vida" -, fica apenas aqui a provocação da riqueza de pontos de partida frente a uma rede de causalidades que enreda o problema de saúde - na maioria das vezes, tomados apenas em sua aparência, e a partir de seus descritores (D1, D2, D3,...), como únicos pontos de partida dos processos de trabalho de produção em suportes técnicos e que toma a comunicação como "elaboração, distribuição e avaliação de produtos em linguagens adequadas", como nos propõem as abordagens teórico-metodológicas de Schanonn e Schramm ${ }^{15}$. O próprio PES e sua crítica com base no agir comunicativo definem algumas "tipologias" de estratégias a serem adotadas, apontando outros modos de abordar um problema, que, no que diz respeito a planejar e definir ações comunicacionais, devem ser consideradas (Rivera, 1995).

Ao mesmo tempo, os chamados "produtos comunicativos" devem ter sua eficácia avaliada, ao longo de sua existência, como ação discursiva, e na perspectiva de "resultados" - nem sempre os esperados e nem sempre verificáveis por metodologias quali-quantitativas tradicionais de avaliação em comunicação ${ }^{16}$, já que passam a fazer parte dessa discursividade ampliada ou intertextualidades, e da permanente fluidez dos processos sociais complexos.

Compreendidos os discursos sociais como intertextos, ações que nomeiam $e$ transformam a realidade (mesmo podendo estar imobilizados em papel, filme, vídeo, fotografia) e que estão em ação permanente no fervilhar de nosso dia-adia, as teias discursivas que "explicam" e respondem a um problema de saúde concreto estarão em movimento contínuo, num amplo espectro de ações entre sujeitos em situação.

Ressaltamos que, no caso da saúde, o processo de definição de ações comunicacionais depende necessariamente da melhor compreensão possível de situações que são específicas e complexas e representam o domínio do sofrimento e das fragilidades humanas e de um mundo de práticas sociais ritualizadas, repleto de fugas, derivas, desvios - a reivindicar, talvez, metodologias de pesquisa de recorte longitudinal. Processos que não se dão de forma linear e pontual nos âmbitos dos fatos aparentes, das acumulações e das regras do jogo, como na proposta matusiana, mas num permanente (re)posicionamento discursivo dos sujeitos ao longo do tempo, e numa permanente transformação daquilo que é percebido, ou "explicado".

Desta forma, cabe-nos o exercício do aprendizado constante; de lidar com o embate cotidiano entre posições discursivas, e equipar o olhar para esta discursividade ampliada extremanente fluida e móvel - apreensível apenas em suas cristalizações, na forma de situações concretas. Situações em que o cálculo racional entra e é refeito - ou "se perde" para uns. Situações, portanto, carregadas de um inapreensível que nos convoca permanentemente a olhar das mais variadas formas e nos mais variados tempos, um mundo de delicadezas: de "pistas", "traços", "rastros", "murmúrios", que se interpõem entre o eu e o outro dos processos de planificação, como nos lembra Certeau (1995). Afinal, o grande desafio da gestão comunicativa seria este fazer cotidiano permanente. $\mathrm{O}$ mesmo que move o instrumentista atento ao interior da orquestra - um
${ }^{15}$ Estes modelos teóricos estão tratados de forma extensiva em Pitta, 2001.

${ }^{16}$ Sobre o tema, ver Jensen \& Jankowski, 1993. 
entre múltiplos instrumentos, um entre múltiplas vozes. Muitos num esforço interminável de conferir harmonia àquilo que pertence, de forma irremediável, à dimensão de uma "não-ordem".

\section{Agradecimentos}

À Renata C. Ruiz, pelo apoio e sugestões ao texto, $e$ à Ronari de Faria $e$ ao Ruben Fernandes, pelo apoio em informática.

Agradecimento especial de Áurea da Rocha Pitta aos pareceristas deste artigo, que possibilitaram, à primeira autora, um rico e dinâmico diálogo anônimo, cujo fruto é esta primeira parceria com o professor Rivera.

\section{Referências}

ACURCIO, F. A.; SANTOS, M. A. A aplicação de um método de planejamento local: relato de uma experiência em Iguatu. In: OPS/OMS. Planejamento e programação local da vigilância da saúde no distrito sanitário. Brasília, 1994. Série Desenvolvimento de Serviços de Saúde, 13.

ARTMANN, E. Planejamento estratégico-situacional no nível local. Rio de Janeiro: COEP/UFRJ, 2000. (Cadernos da Oficina Social 3).

AZEVEDO, F. A. Agendamento da política. In: RUBIM, A. A. C. (Org.). Comunicação e política - conceitos e abordagens. Salvador: Edufba, 2004.

BOLAÑO, C. La centralidad de la economia política de la comunicación (EPC) en la construcción del campo acadêmico de la comunicación: una contribuición crítica. In: ENCONTRO LATINO DE ECONOMIA POLÍTICA DA INFORMAÇÃO, COMUNICAÇÃO E CULTURA, 5., 2005, Salvador. Anais... Salvador, 2005.

CAMARGO JR, K. R. Das necessidades de saúde à demanda socialmente constituída. In: PINHEIRO, R.; MATTOS, R. A. Construção social da demanda. Rio de Janeiro: IMS/UERJ-CEPESC-ABRASCO, 2005. p.91-101.

CAMPOS, G. W. S. Um método para análise e co-gestão de coletivos. 2.ed. São Paulo: Hucitec, 2005.

CAMPOS, G. W. S. Saúde, Paidéia. São Paulo: Hucitec, 2003.

CECÍLIO, L. C. O. As necessidades de saúde como conceito estruturante na luta pela integralidade em saúde. In: PINHEIRO, R.; MATTOS, R. A. Os sentidos da integralidade na atenção e no cuidado à saúde. Rio de Janeiro: IMS/UERJ, CEPESC, ABRASCO, 2006. p.113-26.

CERTEAU, M. A cultura no plural. Campinas: Papirus, 1995.

CERTEAU, M. A invenção do cotidiano: artes de fazer. Petrópolis: Vozes, 1994.

DE MARINIS, M. Semiotica del teatro - l'analisi testuale dello spettacolo. Milão: Bompiani, 1982.

FLORES, F. Inventando la empresa del siglo XXI. Santiago: Hataché, 1989.

JENSEN, K. B.; JANKOWSKI, N. W. (Orgs.). Metodologias cualitativas de investigación en comunicación de massas. Barcelona: Bosh Casa Editorial, 1993.

LACERDA, A.; VALLA, V. V. As práticas terapêuticas de cuidado integral à saúde como proposta para aliviar o sofrimento. In: PINHEIRO, R; MATTOS, R. A. (Orgs.). Cuidado: as fronteiras da integralidade. Rio de Janeiro: IMS/ UERJ, CEPESC, ABRASCO, 2005. p.91-102.

LEFEVRE, F.; LEFEVRE, A. M. C. Promoção de saúde: a negação da negação. Rio de Janeiro: Vieira \& Lent, 2004.

LUZ, M. T. Políticas de descentralização e cidadania: novas práticas de Saúde no Brasil atual. In: PINHEIRO, R.; MATTOS, R. A. Os sentidos da integralidade na atenção e no cuidado à Saúde. Rio de Janeiro: IMS/UERJ, CEPESC, ABRASCO, 2006. p.39-64.

MATUS, C. Política, planejamento e governo. Brasília: Editora Ipea, 1993.

MATUS, C. Politica y plan. 2.ed. Caracas: Iveplan, 1984. 
PITTA, A. M. R.; RIVERA, F. J. U.

MENDES, E. V. Uma agenda para a saúde. São Paulo: Hucitec,1996.

MERHY, E.; MAGALHÃES JR., H. M.; RIMOLI, J.; FRANCO, T. B.; BUENO, W. S. (Orgs.). O trabalho em saúde: olhando e experenciando o SUS no cotidiano. São Paulo: Hucitec, 2004.

MOISÉS, J. A. Democratização e cultura política de massas no Brasil. Lua Nova, n.26, p.5-45, 1992.

PINTO, M. J. Comunicação e discurso: introdução à análise de discursos. São Paulo: Hacker Editores, 1999.

PINTO, M. J. As marcas lingüísticas da enunciação. Rio de Janeiro: Numen, 1994.

PITTA, A. M. R. Comunicação, democracia e promoção da saúde: em busca de uma abordagem teóricoconceitual. Rev. Saúde em Debate, v.28, n.67, p.176-83, 2004.

PITTA, A. M. R. Comunicação, promoção da saúde e democracia: políticas e estratégias de comunicação no Sistema Único de Saúde no Brasil. 2001. Tese (Doutorado) - Escola de Comunicação, Universidade Federal do Rio de Janeiro, Rio de Janeiro.

PITTA, A. M. R. Estratégias de comunicação e prevenção da aids: estudo de caso em Salvador/Bahia Interface - Comunic., Saúde, Educ, v.2, n.2, p.23-45, 1998.

PITTA, A. M. R.; OLIVEIRA, V. C. (Orgs.) Saúde e comunicação: visibilidades e silêncios. São Paulo: Hucitec, 1995.

SÁ, M. C. Planejamento estratégico em saúde: problemas conceituais e metodológicos. 1993.

Dissertação (Mestrado) - Escola Nacional de Saúde Pública, Fundação Oswaldo Cruz, Rio de Janeiro.

TEIXEIRA, R. R. O acolhimento num serviço de saúde entendido como uma rede de conversações. In: PINHEIRO, R.; MATTOS, R. Construção da integralidade: cotidiano, saberes e práticas de saúde. Rio de Janeiro: Abrasco, 2003. p.89-111.

TESTA, M. O pensamento estratégico em saúde. In: RIVERA, F. J. U. (Org.). Planejamento e programação em saúde: um enfoque estratégico. São Paulo/Rio de Janeiro: Cortez EditoralABRASCO,1989. p.59-76.

RIVERA, F. J. U. (Org.). Análise estratégica em saúde e gestão pela escuta. Rio de Janeiro: Fiocruz, 2003.

RIVERA, F. J. U. (Org.). Agir comunicativo e planejamento social: uma crítica ao enfoque estratégico. Rio de Janeiro: Fiocruz, 1995.

VERÓN, E. A produção do sentido. São Paulo: Cultrix/USP, 1980.

PITTA, A. M. R.; RIVERA, F. J. U. Sobre puntos de partida: la planificación en comunicación y la integralidad de la atención a la salud. Interface - Comunic., Saúde, Educ., v.10, n.20, p.395-410, jul/dez 2006.

El texto propone, como punto de partida de la planificación de la comunicación, el momento explicativo de la Planificación Estratégica-Situacional - PES, ampliamente difundido en el campo de la salud colectiva. En este contexto, el texto establece relaciones entre conceptos de la planificación estratégica situacional e una economía política del significante, basado en diferentes momentos de la producción y del sondeo de los autores a dinámicas institucionales y relaciones servicios de salud-población en ámbito local.

PALABRAS CLAVE: comunicación en salud. servicios de salud. atención a la salud.

Recebido em 27/09/05. Aprovado em 07/07/06. 